\title{
Stationary optical solitons with nonlinear chromatic dispersion for Lakshmanan-Porsezian-Daniel model having Kerr law of nonlinear refractive index
}

\author{
${ }^{1}$ Abdullahi Rashid Adem, ${ }^{1}$ Basetsana Pauline Ntsime, ${ }^{2,3,4,5}$ Anjan Biswas, \\ ${ }^{2}$ Salam Khan, ${ }^{3}$ Abdullah Khamis Alzahrani and ${ }^{6}$ Milivoj R. Belic \\ ${ }^{1}$ Department of Mathematical Sciences, University of South Africa, UNISA-0003, \\ South Africa \\ ${ }^{2}$ Department of Physics, Chemistry and Mathematics, Alabama A\&M University, \\ Normal, AL 35762-4900, USA \\ ${ }^{3}$ Mathematical Modeling and Applied Computation (MMAC) Research Group, \\ Department of Mathematics, King Abdulaziz University, Jeddah-21589, Saudi Arabia \\ ${ }^{4}$ Department of Applied Mathematics, National Research Nuclear University, 31 \\ Kashirskoe Hwy, Moscow-115409, Russian Federation \\ ${ }^{5}$ Department of Mathematics and Applied Mathematics, Sefako Makgatho Health \\ Sciences University, Medunsa-0204, Pretoria, South Africa \\ ${ }^{6}$ Science Program, Texas A\&M University at Qatar, PO Box 23874, Doha, Qatar
}

Received: 25.01 .2021

\begin{abstract}
We study stationary optical solitons for the case of LakshmananPorsezian-Daniel model with nonlinear chromatic dispersion and a Kerr law of nonlinear refractive index. The solution is expressed in terms of a special function and its structure is described in details.
\end{abstract}

Keywords: chromatic dispersion, stationary solitons

UDC: 535.32

\section{Introduction}

A delicate and sustained balance between the chromatic dispersion (CD) and the nonlinearity (of a Kerr or some other type) associated with refractive index of a fibre give rise to optical solitons, which can propagate across inter-continental distances. However, one can observe a preposterous effect if this balance is compromised [1-10]. There are a couple of models addressing this issue. These are a nonlinear Schrödinger's equation with various forms of nonlinear refractive index and a Sasa-Satsuma equation $[1,5,6]$. The present work addresses a similar situation using a Lakshmanan-Porsezian-Daniel (LPD) equation [8]. We are going to study this model in a case when the $\mathrm{CD}$ gets distorted to a nonlinear form. Then mobile solitons can become stationary. We illustrate this physical phenomenon by means of mathematical analysis.

The governing LPD equation with the nonlinear $\mathrm{CD}$, which describes soliton propagation through optical fibres, can be expressed in its dimensionless form:

$$
i q_{t}+a\left(|q|^{n} q\right)_{x x}+b|q|^{2} q=c q_{x x x x}+\alpha\left(q_{x}\right)^{2} q^{*}+\beta\left|q_{x}\right|^{2} q+\gamma|q|^{2} q_{x x}+\delta q^{2} q_{x x}^{*}+s|q|^{4} q
$$

Here $q(x, t)$ describes the wave profile and represents a complex-valued function. The two independent variables $x$ and $t$ in Eq. (1) are respectively spatial and temporal coordinates, the remaining coefficients are real valued, and $i=\sqrt{-1}$. The $a$ coefficient corresponds to the nonlinear $\mathrm{CD}$ and $b$ accounts for the self-phase modulation stemming from the Kerr law for nonlinear 
refractive index. On the right-hand side of Eq. (1), $c$ represents the fourth-order dispersion coefficient and $s$ is associated with quintic nonlinearity. The remaining terms involving $\alpha, \beta, \gamma$ and $\delta$ describe the nonlinear dispersion and the related physical phenomena. The power-law nonlinearity factor $n$ indicates departure from the linear CD. The first term $q_{t}$ governs linear temporal evolution of the soliton pulse, while $q_{x}$ and $q_{x x x}$ are the first-order and fourth-order spatial dispersions, respectively. Finally, $q^{*}$ and $q^{*}{ }_{x x}$ denote complex conjugates respectively of the wave field and the $\mathrm{CD}$. This model will be addressed to reveal stationary solitons.

\section{Stationary solitons}

The presence of nonlinear CD leads to stationary solitons [3, 4]. The starting hypothesis for these solitons is given by

$$
q(x, t)=\varphi(x) e^{i \lambda t}
$$

Substituting Eq. (2) into Eq. (1) and transforming it to an ordinary differential equation results in the relation

$$
\begin{gathered}
\text { an }(n+1) \phi^{n+2}(x)\left\{\phi^{\prime}(x)\right\}^{2}+a(n+1) \phi^{n+3}(x) \phi^{\prime \prime}(x)+b \phi^{6}(x)-c \phi^{3}(x) \phi^{(4)}(x) . \\
-\phi^{4}(x)\left[\lambda+(\alpha+\beta)\left\{\phi^{\prime}(x)\right\}^{2}\right]-(\gamma+\delta) \phi^{5}(x) \phi^{\prime \prime}(x)=0
\end{gathered} .
$$

Here $\varphi(x)$ is the amplitude component of the stationary wave and $\lambda$ its wave number. For integrability, one must select the value

along with

$$
c=0,
$$

and

$$
\alpha+\beta=0,
$$

This simplifies the LPD model as follows:

$$
\gamma+\delta=0
$$

$$
i q_{t}+a\left(|q|^{n} q\right)_{x x}+b|q|^{2} q=\alpha\left\{\left(q_{x}\right)^{2} q^{*}-\left|q_{x}\right|^{2} q\right\}+\gamma\left\{|q|^{2} q_{x x}-q^{2} q_{x x}^{*}\right\}+s|q|^{4} q .
$$

Consequently, the ordinary differential equation given by Eq. (3) reduces to

$$
a n(n+1) \phi^{n+2}(x)\left\{\phi^{\prime}(x)\right\}^{2}+a(n+1) \phi^{n+3}(x) \phi^{\prime \prime}(x)-\lambda \phi^{4}(x)+b \phi^{6}(x)-s \phi^{8},
$$

where $\varphi^{\prime}(x)$ and $\varphi^{\prime \prime}(x)$ represent respectively the first- and second-order dispersions of the soliton. Eq. (8) admits a Lie translational point symmetry, namely $\partial / \partial x$.

Implementing this symmetry, integrating Eq. (8) and discarding integration constants yields in the solution

$$
x= \pm \frac{1}{n} \sqrt{\frac{2 a(n+1)(n+2) \phi^{n}}{\lambda}} F_{1}\left(\frac{n}{4} ; \frac{1}{2}, \frac{1}{2} ; \frac{n+4}{4} ; B_{1}, B_{2}\right),
$$

where

$$
\begin{aligned}
& B_{1}=\frac{2(n+2)(n+4) s \phi^{2}}{b(n+2)(n+6)-\sqrt{(n+2)(n+6)\left\{b^{2}(n+2)(n+6)-4 \lambda s(n+4)^{2}\right\}}}, \\
& B_{2}=\frac{2(n+2)(n+4) s \phi^{2}}{\sqrt{(n+2)(n+6)\left\{b^{2}(n+2)(n+6)-4 \lambda s(n+4)^{2}\right\}}+b(n+2)(n+6)},
\end{aligned}
$$


and the Appell's hyper-geometric function is defined as

$$
F_{1}\left(\alpha ; \beta, \beta^{\prime} ; \gamma ; x, y\right)=\sum_{m_{1}=0}^{\infty} \sum_{m_{2}=0}^{\infty} \frac{(\alpha)_{m_{1}+m_{2}}(\beta)_{m_{1}}\left(\beta^{\prime}\right)_{m_{2}}}{m_{1} ! m_{2} !(\gamma)_{m_{1}+m_{2}}} x^{m_{1}} y^{m_{2}},
$$

Here $m_{1}$ and $m_{2}$ are running indices of summation operations and the Pochhammer symbol is defined as

$$
(p)_{n}=\left\{\begin{array}{lc}
1 & n=0, \\
p(p+1) \cdots(p+n-1) & n>0 .
\end{array}\right.
$$

The convergence criteria for the series entering Eq. (12) are as follows:

$$
|x|<1 \text { and }|y|<1
$$

Considering Eq. (9), one can arrive at

$$
|\phi(x)|<\left[\frac{\left|b(n+2)(n+6)-\sqrt{(n+2)(n+6)\left\{b^{2}(n+2)(n+6)-4 \lambda s(n+4)^{2}\right\}}\right|}{2(n+2)(n+4)|s|}\right]^{\frac{1}{2}} .
$$

This testifies that the solution of Eq. (1) must remain bounded for stationary solitons to exist.

\section{Conclusion}

In the present work, we have demonstrated for the first time a very interesting and promising result obtained for the LPD model combined with the Kerr law for the nonlinear refractive index and the nonlinear CD. Namely, the stationary soliton solution has been addressed. Here the main promise is that the model can be extended to address the other forms of the nonlinear refractive index, which are not of the Kerr type. Moreover, the model has to be examined for the cases of birefringent fibres and differential group delay. The latter studies are in progress.

\section{Acknowledgement}

One of us (M.R.B.) thanks Q.N.R.F. for financial support of this research work under the grant NPRP 11S-1246-170033.

The authors declare no conflict of interest.

\section{References}

1. Adem A R, Ekici M, Biswas A, Asma M, Zayed E M E, Alzahrani A K and Belic M R, 2020. Stationary optical solitons with nonlinear chromatic dispersion having quadratic-cubic law of refractive index. Phys. Lett. A. 384: 126606.

2. Adem A R, Ntsime B P, Biswas A, Asma M, Ekici M, Moshokoa S P, Alzahrani A K and Belic M R, 2020. Stationary optical solitons with Sasa-Satsuma equation having nonlinear chromatic dispersion. Phys. Lett. A. 384: 126721.

3. Biswas A, Ekici M, Sonmezoglu A and Belic M, 2018. Stationary optical solitons with nonlinear group velocity dispersion by extended trial function scheme. Optik. 171: 529-542.

4. Ekici M, Sonmezoglu A, Biswas A and Belic M, 2018. Sequel to stationary optical solitons with nonlinear group velocity dispersion by extended trial function scheme. Optik. 172: 636650.

5. Geng Y and Li J, 2008. Exact solutions to a nonlinearly dispersive Schrödinger equation. Appl. Math. Comp. 195: 420-439.

Ukr. J. Phys. Opt. 2021, Volume 22 
6. Yan Z, 2006. Envelope compactons and solitary patterns. Phys. Lett. A. 355: 212-215.

7. Yan Z, 2006. Envelope compact and solitary pattern structures for the GNLS(m,n,p,q) equations. Phys. Lett. A. 357: 196-203.

8. Yan Z, 2007. New exact solution structures and nonlinear dispersion in the coupled nonlinear wave systems. Phys. Lett. A. 361: 194-200.

9. Zhang Z, Liu Z, Miao X and Chen Y, 2011. Qualitative analysis and traveling wave solutions for the perturbed nonlinear Schrodinger's equation with Kerr law nonlinearity. Phys. Lett. A. 375: $1275-1280$.

10. Zhang Z, Li Y, Liu Z and Miao X, 2011. New exact solutions to the perturbed nonlinear Schrodinger's equation with Kerr law nonlinearity via modified trigonometric function series method. Commun. Nonlin. Sci. Num. Simul. 16: 3097-3106.

Abdullahi Rashid Adem, Basetsana Pauline Ntsime, Anjan Biswas, Salam Khan, Abdullah Khamis Alzahrani and Milivoj R. Belic. 2021. Stationary optical solitons with nonlinear chromatic dispersion for Lakshmanan-Porsezian-Daniel model having Kerr law of nonlinear refractive index. Ukr.J.Phys.Opt. 22: 83 - 86. doi: 10.3116/16091833/22/2/83/2021

Анотація. Вивчено стаиіонарні оптичні солітони для моделі Лакшманана-ПорсезіанаДаніеля з нелінійною хроматичною дисперсією та законом Керра для нелінійного показника заломлення. Розв'язок виражено в термінах спеціальної функиії, а також детально описано його структуру. 